\title{
Prevalence and risk factors of prolonged QTc interval in type 2 diabetic patients; impact of the type of treatment and quality of glycemic control
}

V. Ninkovic ${ }^{1}$, M. Dobric ${ }^{2}$, DJ. Jakovljevic ${ }^{3}$, S. Ninkovic ${ }^{4}$, G. Bubanja ${ }^{1}$, V. Miloradovic ${ }^{4}$, D. Zivojinovic ${ }^{1}$, M. $^{2}$ Babic $^{1}$, B. Milovanovic ${ }^{1}$, V. Giga ${ }^{2}$

(1) Specialistic Hospital "Merkur", the National Educational Centre for Diabetes, Vrnjacka Banja, Serbia

(2) Clinic of Cardiology, Clinical Centre of Serbia, University of Belgrade, Belgrade, Serbia

(3) Newcastle University, Medical School, Institute for Ageing and Health, Newcastle upon Tyne, United Kingdom

(4) Clinical Centre Kragujevac, University of Kragujevac, Faculty of Medicine, Kragujevac, Serbia

Introduction: A prolonged heart rate-adjusted QT (QTc) interval is considered a risk factor for malignant arrhythmias and sudden cardiac death. The aim of this study was to assess the prevalence and predictors of prolonged QTc interval in patients with type 2 diabetes (T2D).

Methods: This study included 501 T2D patients treated in National Educational Centre for Diabetes, Specialistic Hospital (SH) "Merkur", Vrnjacka Banja, Serbia, from September 2011 to July 2012 (table 1). We analysed baseline clinical and laboratory data including: age, gender, duration of diabetes, body mass index, presence of coronary artery disease (CAD), presence of polyneuropathy, type of treatment, renal function, and the presence of traditional risk factors for CAD. In all patients 6-8 blood samples were taken within $24 \mathrm{~h}$ and following parameters of glycoregulation were analysed: fasting blood glucose (FBG), mean value of blood glucose (MBG), and mean amplitude of glucose excursion (MAGE), as well as $\mathrm{HbA1c}$ (table 2). In baseline ECG QT interval was measured using digital ruler. Heart rate corrected QT interval (QTc) was calculated using Bazett's formula, considering QTc> $440 \mathrm{msec}$ as prolonged, and QTC> 500 msec as significantly prolonged.

Table 1. Basic clinical and demographic characteristics of diabetic type 2 population treated in $\mathrm{SH}$ „Merkur“, Vrnjacka Banja

\begin{tabular}{|l|l|}
\hline Characteristics & All Patients \\
\hline Number of Patients & 501 \\
\hline Female & 224 \\
\hline Age & $60.4 \pm 8.1$ (years) \\
\hline Mean diabetes duration & $9.9 \pm 6.8$ (years) \\
\hline Hypertension & 394 \\
\hline Coronary artery disease & 114 \\
\hline Chronic kidney disease & 43 \\
\hline
\end{tabular}


Table 2. The observed variables and their definition

Varaible

Age

$\operatorname{Sex}$

\section{Diabetes duration}

Body mass index

Hypertension

Actual TA (systolic, diastolic)

Coronary artery disease

Chronic kidney disease

CVA (ishaemic, haemorhagic, TIA)

Smoking (actual, former)

Distal symetric polyneuropathy

Retinopathy

(nonproliferative, proliferative)

Type of treatment

(Sulfonilurea, metformin, insulin, and combination)

HbA1c, Fasting blood glucosae, Mean blood glucosae

MAGE
Definition

The values of SBP/DBP $\geq 140 / 90 \mathrm{mmHg}$ in two measurements or on

antihypertensive treatment

Previous ACS, CABG, PCI, positive coronarography findings, positive exercise stress test, typical effort angina, or Minnesota code 1.1 and 1.2 in ECG tracings.

eGFR<60 $\mathrm{ml} / \mathrm{min} / 1.73 \mathrm{~m}^{2}$ (MDRD)

Positive EMNG findings or symptomps and signs compatible with polyneuropathy including determination of vibratory perception threshhold

Arithmetic mean of absolute diferences of peak and subsequent nadir of glucosae values in daily profile of glycemia, while only diferneces $>1 S D$ of mean value of glycemia are taken into account 
Results: Prolonged QTc ( $>440 \mathrm{msec}$ ) was present in $44 \%$ (221) of our patients, however, prolongation of QTc > 500 msec was observed in only $2 \%$ (10) of patients. QTc duration $>440 \mathrm{~ms}$ was associated in univariable analysis with age, female gender, treatment with sulfonylurea, and different parametres of glycemic control (HbA1c, FBG, MBG, and MAGE), as well as with the history of CAD and presence of diabetic polyneuropathy (table 3). However, MBG $(B=2.192, p<0.001)$, female gender $(B=8.844$, $p<0.001)$, history of $C A D(B=8.636, p=0.001)$, and treatment with sulfonylurea $(B=5.198, p=0.027)$ remained independently associated with QTc $>440 \mathrm{~ms}$ in multivariable analysis (table 4). On the other hand, QTC > 500 msec was independently related only to the history of CAD and MBG (OR=12.145, 95\% $\mathrm{Cl} 1.818-81.146$ and $\mathrm{OR}=1.457,95 \% \mathrm{Cl} 1.154-1.840$, respectively, $\mathrm{p}<0.001$ for both) (table 5).

Table 3. Predictors of QTc>440 ms-univariable analysis

\begin{tabular}{|l|c|c|}
\hline Varible & B & p \\
\hline Age & 0.427 & 0.002 \\
\hline Female sex & 10.724 & $<0.001$ \\
\hline Treatment with sulfonilurea & 5.707 & 0.012 \\
\hline Coronary artery disease & 10.508 & $<0.001$ \\
\hline Polineuropathy & 7.335 & 0.004 \\
\hline HbA1c & 2.660 & 0.002 \\
\hline Fasting blood glucosae & 1.763 & $<0.001$ \\
\hline MAGE & 1.463 & 0.009 \\
\hline Mean blood glucosae & 2.168 & $<0.001$ \\
\hline
\end{tabular}

Table 4. Predictors of QTc $>440$ ms-multivariable analysis

\begin{tabular}{|l|c|c|}
\hline Variable & B & \multicolumn{1}{|c|}{$\mathbf{p}$} \\
\hline Mean blood glucosae & 2.192 & $<0.001$ \\
\hline Female sex & 8.844 & $<0.001$ \\
\hline Coronary artery disease & 8.636 & 0.001 \\
\hline Treatment with sulfonilurea & 5.198 & 0.027 \\
\hline
\end{tabular}


Table 5. Predictors of QTc>500 ms-multivariable analysis

\begin{tabular}{|l|c|c|}
\hline Variable & OR $(95 \% \mathrm{Cl})$ & P \\
\hline Coronary artery disease & $12.145(1.818-81.146)$ & $<0.001$ \\
\hline Mean blood glucosae & $1.457(1.154-1.840)$ & $<0.001$ \\
\hline
\end{tabular}

Conclusions: Prolonged QTc was highly prevalent with $44 \%$ of our T2D patients demonstrating QTc $>440$ msec. However, significantly prolonged QTc of $>500 \mathrm{msec}$, which is clearly associated with risk of malignant arrhythmias, was indentified in only $2 \%$ of our patients, and was independently related to the mean blood glucose and the history of CAD. 